\title{
LARVAL TRANSPORT AND COASTAL UPWELLING: AN APPLICATION OF HF RADAR IN ECOLOGICAL RESEARCH
}

\author{
By Eric Bjorkstedt and Jonathan Roughgarden
}

High-frequency (HF)

radar is a recent addition to ecologists' remote sensing toolbox... .
F near-surface currents strongly affect the likelihood of surviving as a planktonic larva and arriving at a suitable location, say, a rocky coastline, a kelp forest, or an estuary, to begin life as a juvenile or adult (i.e.. to "recruit" to a population). High-frequency (HF) radar is a recent addition to ecologists' remote sensing toolbox that offers the ability to observe oceanographic processes directly affecting larval ecology at scales appropriate for understanding recruitment dynamics in marine populations.

In this article. we report on our application of $\mathrm{HF}$ radar in research focusing on larval ecology at coastal upwelling fronts off central California. Coastal upwelling regions, such as that off the western United States, pose an interesting set of ecological questions that can be addressed with data from $\mathrm{HF}$ radar. During active coastal upwelling, the same currents supplying nutrients that support high productivity put planktonic larvae at risk of being swept offshore and away from coastal habitats. Indeed, some fish and invertebrate populations exhibit reduced recruitment success during periods of increased offshore advection (Bailey, 1981; Roughgarden et al., 1988). Coastal upwelling fronts, which form between cold upwelled water near the coast and warmer, fresher surface waters offshore, may reduce offshore transport of planktonic larvae, thereby facilitating nearshore retention and return of larvae to coastal recruitment sites. To test this hypothesis and to assess the utility of HF radar as an ecological tool, we sampled zooplankton along transects spanning coastal upwelling fronts, monitored recruitment to intertidal barnacle populations during the upwelling seasons of 1993 and 1994, and compared our data to coincident HF radar observations.

We used radial data obtained from a single SeaSonde HF radar deployed at Granite Canyon, CA

Eric P. Bjorkstedt. Department of Biological Sciences. Stanford University. Stanford. CA 94305: Jonathan Roughgarden, Department of Biological Sciences and Department of Geophysics. Stanford University, Stanford. CA 94305, USA. $\left(36^{\circ} 25.9^{\prime} \mathrm{N}, 121^{\circ} 55.0^{\prime} \mathrm{W}\right)$. Before calculating currents, we 1 ) discarded radial vectors with a standard error to mean ratio $>0.1$ to ensure data quality, 2) used simple linear interpolation first to fill spatial gaps of $<90^{\circ}$ within a range bin and then to fill temporal gaps of $<24 \mathrm{~h}$ in observations in each observation cell. and 3) applied a low-pass filter (PL64) to remove tidal and other high-frequency signals. Under the assumption that the current is uniform across two observation cells, we calculated currents from pairs of radial observations; each result represented the uniform current that would yield both radial currents used in its calculation.

Using a single radar presents a tradeoff between greater spatial resolution (and the increasing likelihood that the current is indeed similar at 2 points closely arranged in space) and the difficulties associated with the "baseline problem" of determining currents from nearly parallel observations. The baseline problem is exacerbated by violations of the assumption that flow is uniform across neighboring observation cells. We screened our results for clear cases where this occurred; currents were discarded and replaced by interpolation if either 1) they were $>150 \mathrm{~cm} \mathrm{~s}^{-1}$ and within $5^{\circ}$ of perpendicular to the radial vectors used in the calculation or 2) they differed from neighboring vectors by a Euclidean distance $>30 \mathrm{~cm} \mathrm{~s}^{-1}$.

Figure 1 illustrates an example of the resulting low-frequency current field and a coincident satellite Advanced Very High Resolution Radiometer (AVHRR) image of sea-surface temperature. Patterns in the current field generally coincide with thermal structures. For example, the strong current jet flowing offshore west of Point Sur corresponds directly to the tongue of cool water visible in the AVHRR image. The frontal zone between the cool tongue and warmer water to the north is clearly resolved in the current field as a sharp transition between equatorward flow and the current jet. The southwestern front apparent in the satellite image appears as a transition to weaker currents in the warmer water mass. Temporal series of images demonstrate consistent spatial correlation between $\mathrm{HF}$ radar and satellite observations. 


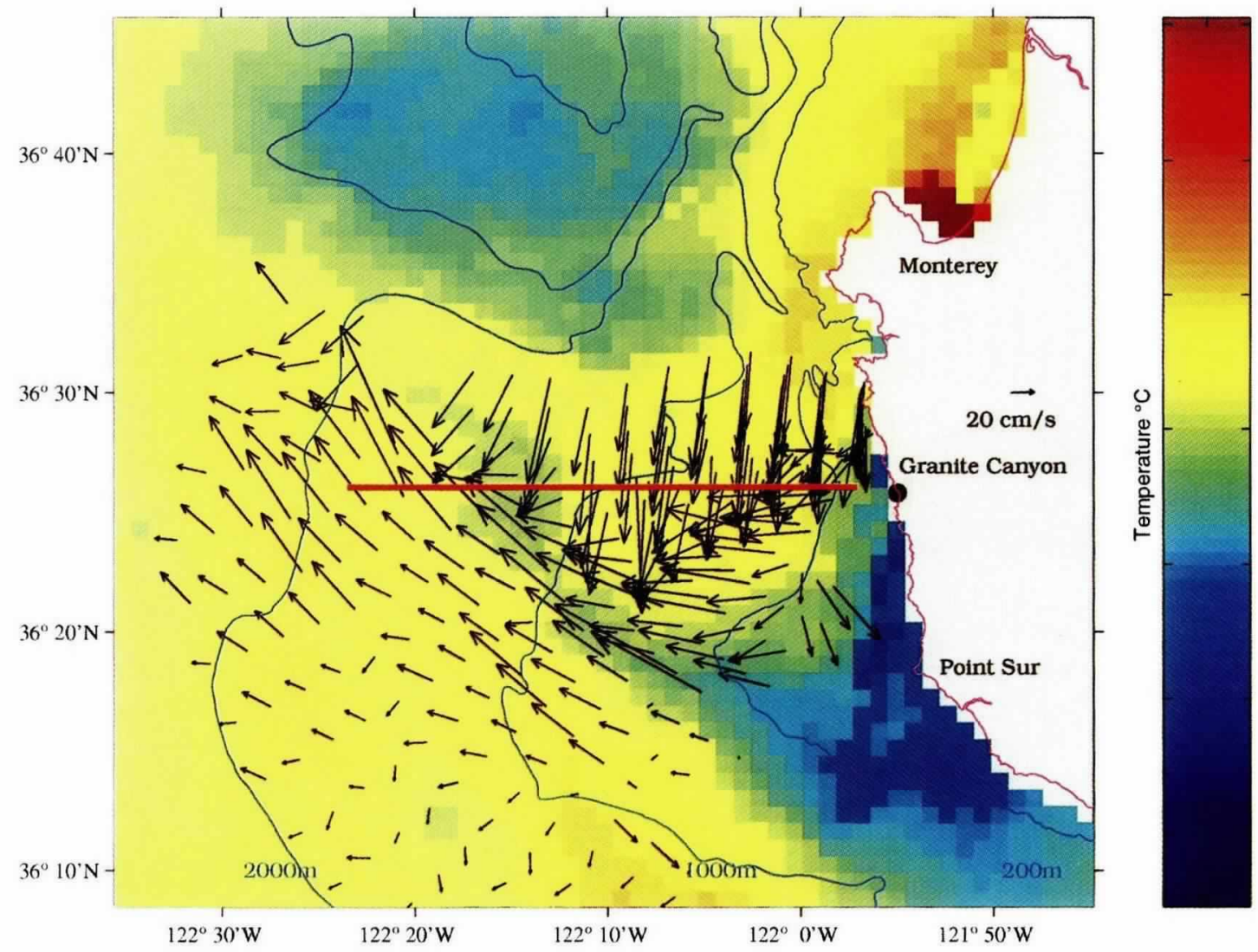

Fig. 1: Surface currents from detided radial data obtained with a single SeaSonde located at Granite Canyon, CA, and satellite AVHRR image of SST for 1700 PST 15 July 1993. Horizontal line shows location of transect data in Figures 2 and 3.

To compare HF radar observations to zooplankton distributions, we calculated divergence from low-frequency surface currents obtained from the SeaSonde data. Convergence zones, marked by negative divergence values, may accumulate buoyant or surface-oriented plankton. Figures 2 and 3 show typical distributions of barnacle and fish larvae, respectively, in relation to divergence and SST. Barnacle larvae are generally bounded inshore of divergences, or accumulate at convergent fronts. Larval fish (mostly rockfish $\mathrm{Se}$ bastes spp., a coastal group) are most abundant in convergence zones associated with temperature fronts. Fish larvae were sampled from a broader depth range than barnacles (upper 27-37 $\mathrm{m}$ and 1 $\mathrm{m}$ of the water column, respectively), and distributions of fish larvae across upwelling fronts were observed to follow the slope of the pycnocline. Slight seaward offsets of peak abundances of fish larvae relative to convergent fronts in the ocean surface may therefore occur, but remain consistent with nearshore retention of larvae by the front.

Observations like those described above represent "snapshots" integrating spawning location, timing and intensity, larval survival, and transport processes. Measuring actual larval transport requires time series of such observations. Figure 4 shows a time series of settlement by competent barnacle larvae to rocks in the upper intertidal zone at a site $15 \mathrm{~km}$ north of the radar site in Granite Canyon in relation to surface currents for a period spanning the sole large recruitment pulse of the 1994 upwelling season. In a sense, rather than tracking a patch of larvae with a ship, we use the rocks along the coast to sample temporal vari-
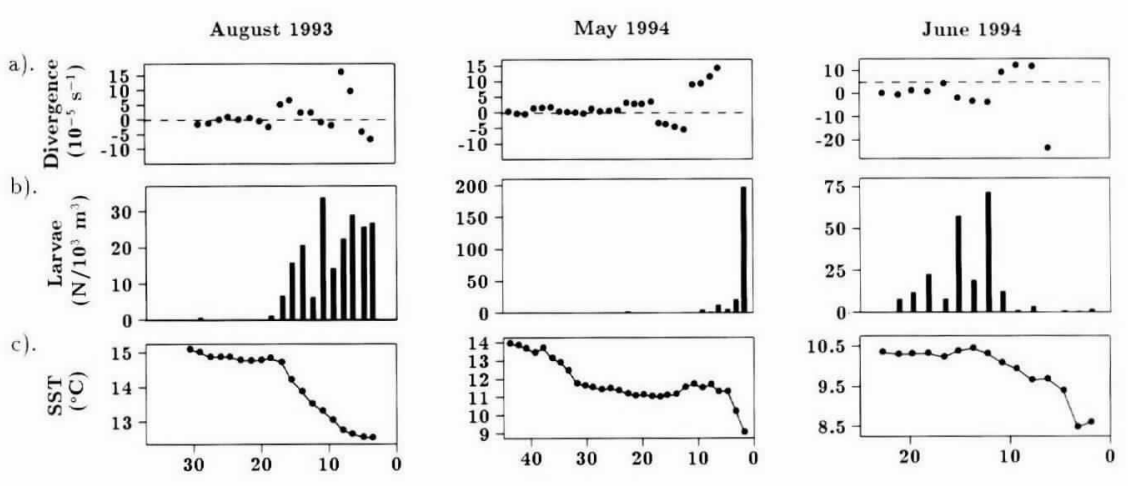

Distance Offshore $(\mathrm{km})$

Fig. 2: Distribution of intertidal barnacle larvae in relation to divergence and SST for 11 August 1993, 4 May 1994, and 26 June 1994. Barnacle larvae were sampled in the upper meter of the water column. For each cruise (a) divergence calculated at each sampling station, (b) abundance of barnacle larvae, and (c) SST. 
a).

b).
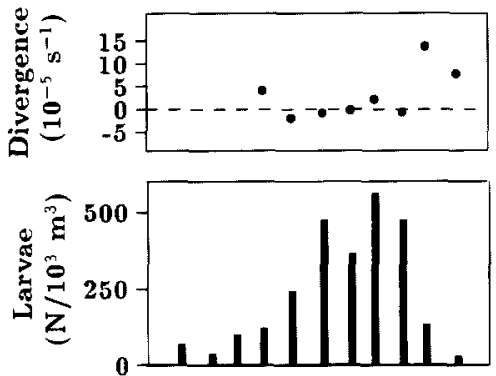

c).

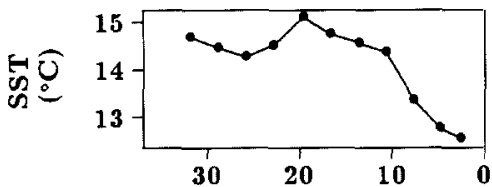

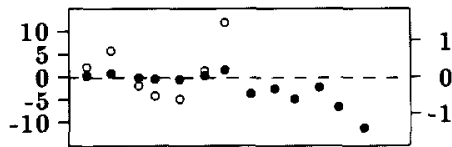
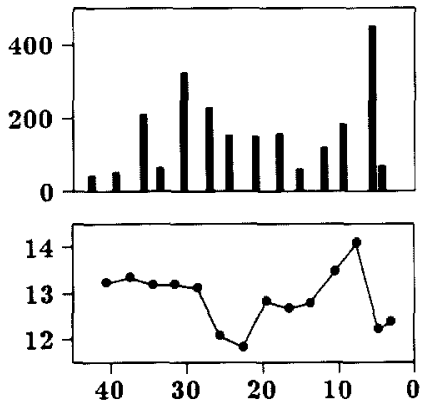
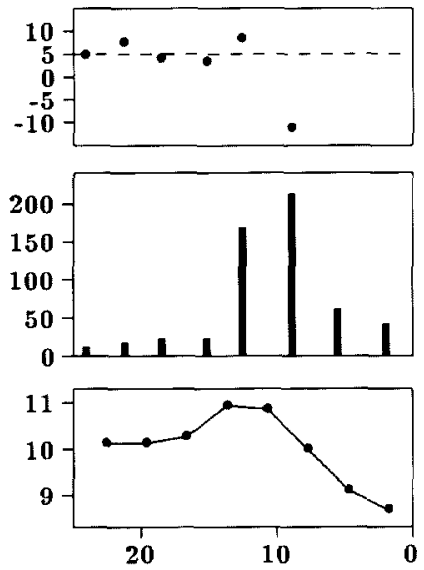

Distance Offshore $(\mathrm{km})$

Fig. 3: Distribution of fish larvae in relation to divergence and SST for 11-12 August 1993, 4-5 May 1994, and 26-27 June 1994. Fish larvae were sampled in the upper 27 meters of the water column (upper 37 meters in May 1994). For each cruise: (a) divergence calculated at each sampling station, (b) abundance of fish larvae, and (c) SST. Note: In the divergence plot for May 1994, divergence (X8) is replotted with $(O)$ at offshore stations to highlight convergence zone associated with an old upwelling front.

\section{$H_{F \text { radar measures }}$}

currents affecting

ecological processes

at important spatial

and temporal ...

scales ... ation in larval abundance at a given location. During typical upwelling conditions (i.e., surface currents flowing to the south and offshore), recruitment is low (Fig. 4, a and b). The onset of the recruitment pulse, presumably because of the return of larvae to the coastal habitat (Farrell et al., 1991), coincided with a rapid transition to onshore currents in response to a strong relaxation in the winds that drive coastal upwelling (Fig. 4, a and c). After northwesterly winds intensified, typical upwelling currents resumed and recruitment rates fell to low levels (Fig. 4, a and d).

The plankton surveys and recruitment time series provide support for hypotheses that 1) convergence at fronts contributes to accumulation of plankton, 2) coastal upwelling fronts facilitate nearshore retention of coastal larvae, and 3) cessation of upwelling and subsequent shoreward transport of larvae during wind relaxation events is an important mechanism causing recruitment in coastal invertebrate populations (Roughgarden $e t$ al., 1988; Farrell et al., 1991).

Fig. 4: Recruitment of barnacle larvae to adult populations in the rocky intertidal zone in relation to changes in surface currents during upwelling relaxation. (a) Recruitment of intertidal barnacles to settlement plates affixed in the rocky intertidal zone at Asilomar ("AB" in Farrell et al., 1991) from 22 April to 29 June 1994. Arrows indicate times of $H F$ radar current maps described below. (b-d) Surface current maps for 1600 PST 4 May, 1600 PST 7 May, and 1600 PST 11 May 1994. The vector on land has a length representing a 50 $\mathrm{cm} \mathrm{s}$ flow.
Just as importantly, the examples above demonstrate the potential of HF radar as a remote sensing technology enabling researchers to monitor and predict the location and transport of planktonic larvae. HF radar measures currents affecting ecological processes at important spatial (1-100 $\mathrm{km}$ ) and temporal (hourly-weekly) scales and captures front-scale variability that is absent in larger scale metrics of upwelling intensity (i.e., the

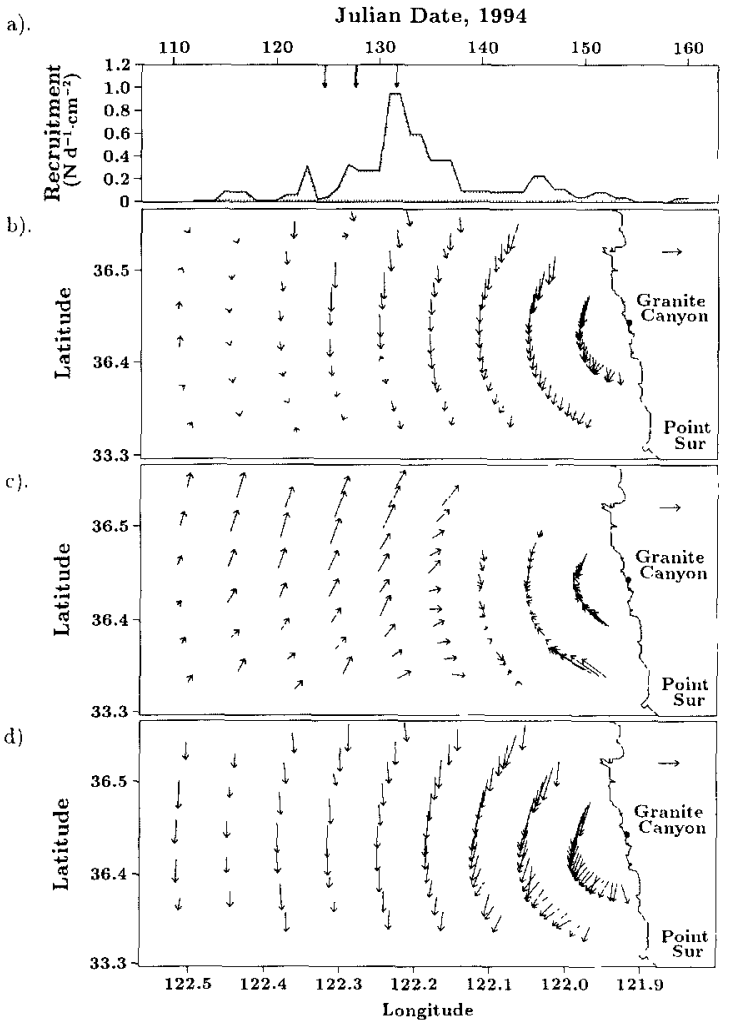


Bakun index). Thus HF radar can support detailed field research and modeling (e.g., Alexander and Roughgarden, 1996) linking upwelling intensity and front structure to marine population dynamics. Such efforts have clear applications in research efforts toward predicting the population dynamics of commercially exploited species and designing effective marine reserves.

\section{Acknowledgments}

We thank Jeff Paduan and Hans Graber for the opportunity to contribute to this issue and Jeff Paduan for preparing Figure 1. Brian Grantham and Yehoshua Shkedy assisted with shipboard plankton sampling. Leslie Rosenfeld provided physical oceanographic data for the cruises and the PL64 filter. Yehoshua Shkedy collected the barnacle recruitment data. We thank the captains and crew of the R/V Point Sur for their valuable assistance during the sampling cruises. This research has been funded by grants NAGW-2159 from NASA and OCE- 9115876 from the NSF. E.B. was supported by an N.S.F. Graduate Research Fellowship.

\section{References}

Alexander, S.E. and J. Roughgarden, 1996: Larval transport and population dynamics of intertidal barnacles: a coupled benthic/oceanic model. Ecol. Monogr. 66. 259275.

Bailey, M.. 1981: Larval transport and recruitment of Pacific Hake Merluccius productus. Mar. Ecol. Prog. Ser. 6. $1-9$.

Farrell. T.M., D. Bracher and J. Roughgarden, 1991: Crossshelf transport causes recruitment to intertidal populations in central California. Limnol. Oceanogr., 36, 279288.

Roughgarden. J., S. Gaines and H. Possingham. 1988: Recruitment dynamics in complex life cycles. Science, 241. 1460-1466. 口

\section{Oceanographic Consortium Selected as Program Office for National Oceanographic Partnership Program}

The Consortium for Oceanographic Research and Education (CORE) has been selected for a $\$ 711,094$ contract to become the Program Office for the National Oceanographic Partnership Program (NOPP). The selection was made by a team representing ten Federal agencies (Office of Naval Research. Oceanographer of the Navy. National Science Foundation, National Oceanic and Atmospheric Administration, National Aeronautics and Space Administration. Minerals Management Service. US Geological Survey, Defense Advanced Research Projects Agency. Department of Energy, and the Environmental Protection Agency).

The primary objectives of NOPP are to promote the national goals of assuring national security, advancing economic development, protecting quality of life. and strengthening science education and communication through improved knowledge of the oceans. NOPP includes $\$ 20.5 \mathrm{M}$ of appropriations for research and educational activities in oceanography awarded recently on a competitive basis. and it establishes the National Oceanographic Research Leadership Council (NORLC), a high-level group. chaired by the Secretary of the Navy and the Administrator of NOAA (vicechair). NOPP was introduced in the US Congress as part of the National Oceanographic Partnership Act by Representative Curt Weldon (R-PA), Chair of the Military Research and Development Subcommittee of the House National Security Committee. With the signature of the Fiscal Year 1997 Defense Authorization by President Clinton last fall, NOPP was initiated.

CORE will begin serving as the Program Office for the National Oceanographic Partnership Program on 14 July. As Program Office, CORE will be responsible for providing technical and administrative support to the NORLC. including assistance in preparation of the legislatively mandated annual report to Congress on the status and plans of the NOPP.

CORE is the Washington, DC based association of U.S. oceanographic research and educational institutions, universities, laboratories and aquaria. The 48 CORE members represent the nucleus of U.S. research and education in the ocean. CORE's President, ADM James D. Watkins, USN (Ret), previously served as Chief of Naval Operations and as Secretary of Energy.

Media contact: Dr. Richard W. Spinrad. Director, CORE

Phone: (202) 232-3900 x219

E-mail: rspinrad@brook.edu 